\title{
Study on Nattokinase-Extraction with two-phase aqueous system
}

\author{
Yingge Yang \\ Department of Bioengineering, Xuzhou Vocational college of Bioengineering, Xuzhou, 221006, \\ China \\ email:ygyang_1982@163,com
}

\begin{abstract}
Keywords: Nattokinase;Two-phase Aqueous Extration;Distribution Behavior
\end{abstract}
\begin{abstract}
The extraction of nattokinase with two-phase aqueous system was studied.Distribution

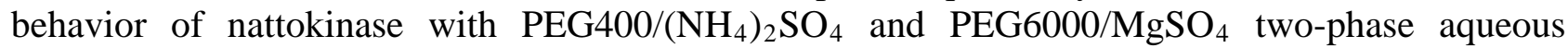
systems were studied respectively. PEG400/( $\left.\mathrm{NH}_{4}\right)_{2} \mathrm{SO}_{4}$ two-phase aqueous system is suitable for the extraction of nattokinase. Various factors affecting the extraction of nattokinase with PEG400/( $\left(\mathrm{NH}_{4}\right)_{2} \mathrm{SO}_{4}$ two-phase aqueous system were studied. The mass fraction of PEG400 was determined to be $24 \%$, The mass fraction of $\left(\mathrm{NH}_{4}\right)_{2} \mathrm{SO}_{4}$ was determined to be $27 \%$, the addition of crude enzyme was determined to be $15 \%$. Under these conditions,purification of nattokinase reached 2.11.
\end{abstract}

\section{Introduction}

Nattokinase is a kind of alkaline protease. The study found that, nattokinase has the ability to dissolve thrombus effectively[1].At present,nattokinase is extracted by the combination of salting out method and two to three step chromatography. Chromatography media is mainly agarose,dextran,cellulose,etc.Although the high pure nattokinase can be obtained,but the cost is high[2].Two-phase aqueous extration techniques refers to the two kinds of polymer or polymer and a salt water solution mixed together[3].Because of the incompatibility between the polymer and the polymer and salt,two phase are formed. Two-phase aqueous extraction technology has the characteristics of mild conditions,easy method,continuous operation. Two-phase aqueous extraction technique has been successfully applied to the separation and purification of biological products[4].Natto was used as materials, the extration technology of nattokinase with two-phase aqueous system has been explored.

\section{Materials and methods}

Raegents used in the study are shown as follow..Natto the laboratory fermentation,PEG400 CR Sinopharm Chemical Reagent Co.Ltd.,PEG6000 CR Sinopharm Chemical Reagent Co.Ltd., $\left(\mathrm{NH}_{4}\right)_{2} \mathrm{SO}_{4}$ AR Xilong Chemical Co.Ltd., $\mathrm{Mg} \mathrm{SO} \mathrm{SO}_{4}$ AR Sinopharm Chemical Reagent Co.Ltd., $\mathrm{NaCl}$ AR Shanghai Guangnuo Chemical Co.Ltd., Fibrinogen BR Sigma,Urokinase 10KU CALBIOCHEM

Apparatus used in the study are shown as follow.Vortex mixing device XW-80A Haimen equipment manufaure Co.Ltd., Super clean worktable SW-CJ-2F Suzhou purification equipment limited company, Biochemical culture box MJ-300BS Shanghai Weicheng Instrument Co.Ltd., Spectrophotometer 756 Shanghai optical instrument factotry.

Crude enzyme liquid was prepared.Fresh fermented natto,adding 2 times volume of sterilized saline,mixed,extracted $24 \mathrm{~h}, 7000 \mathrm{r} / \mathrm{min} 15 \mathrm{~min}$ frozen centrifugation,the supernatant was extracted as crude enzyme liquid.

Two-phase aqueous system was prepared.The amount of $\left(\mathrm{NH}_{4}\right)_{2} \mathrm{SO}_{4}$ was weighed, $\left(\mathrm{NH}_{4}\right)_{2} \mathrm{SO}_{4}$ with $40 \%$ mass fraction was prepared. A certain amount of PEG400 was added. The solution was mixed with mixing device. Two-phase system were formed after resting. The mass fration of $\left(\mathrm{NH}_{4}\right)_{2} \mathrm{SO}_{4}$ and PEG400 were calculated. Two-phase aqueous systems were prepared.

Distribution behavior of nattokinase was studied.Nattokinase enzyme solution was added to 
two-phase aqueous system. The solution was mixed thorough with mixing device. Two-phase system were formed after resting.Comparison $\mathrm{R}$,distribution coefficient $\mathrm{K}$ and recovery of enzyme activity Yt were calculated respectively.

Comparison $\mathrm{R}=$ up phase volum/down phase volum,Distribution coefficient $\mathrm{K}=$ up phase enzyme activity /down phase enzyme activity, Recovery of enzyme activity $\mathrm{Yt}=\mathrm{RK} /(1+\mathrm{RK}) \times 100 \%$

The activity of nattokinase were determined by fibrin plate method.The fibrinogen plate was prepared,9mm oxford cup was placed on the fibrinogen plate.The sample was added to in the oxford cup.Then cultured for $24 \mathrm{~h}$ at $37^{\circ} \mathrm{C}$.The tranparent circle diameter was determined ,the area was calculated.Enzyme activity was calculated according to urokinase standard curve.

Protein concentration was determined by ultraviolet absorption method[5].Protein concentration $(\mathrm{mg} / \mathrm{ml})=1.45 \mathrm{~A} 280 \mathrm{~nm}-0.74 \mathrm{~A} 260 \mathrm{~nm}$

\section{Results}

The phase diagram is often used to represent the formation conditions and the quantitative relationships of the two-phase aqueous system[6]. Substance which formed phase can limitlessly mixed with water.When their composition above the curve,sysytem will be divided into two phases.When their composition below the curve,system can not be separated.The experimental results are as follows. PEG200/( $\left(\mathrm{NH}_{4}\right)_{2} \mathrm{SO}_{4}$ and $\mathrm{PEG} 200 / \mathrm{MgSO}_{4}$ can not form two-phase. PEG400/( $\left(\mathrm{NH}_{4}\right)_{2} \mathrm{SO}_{4}$ can form two-phase. PEG400/MgSO 4 can not form two-phase. PEG6000/( $\left(\mathrm{NH}_{4}\right)_{2} \mathrm{SO}_{4}$ and PEG6000/MgSO 4 can form two-phase.Figure 1 shows that the phase diagram formed by PEG400/( $\left.\mathrm{NH}_{4}\right)_{2} \mathrm{SO}_{4}$ two-phase system. Figure 2 shows that the phase diagram formed by PEG6000/MgSO 4 two-phase system. PEG400/( $\left.\mathrm{NH}_{4}\right)_{2} \mathrm{SO}_{4}$ two-phase formation required a larger fraction of $\left(\mathrm{NH}_{4}\right)_{2} \mathrm{SO}_{4}$. PEG6000/ $\mathrm{MgSO}_{4}$ two-phase formation required a smaller fraction of $\left(\mathrm{NH}_{4}\right)_{2} \mathrm{SO}_{4}$. Maybe due to the larger the molecular weight of PEG,the hydrophobic property,thereby the phase power is increased.

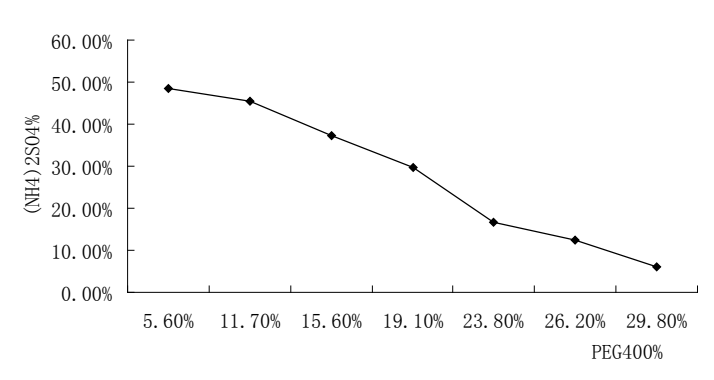

Figure 1 The phase diagram formed by PEG400/( $\left(\mathrm{NH}_{4}\right)_{2} \mathrm{SO}_{4}$ two-phase system.

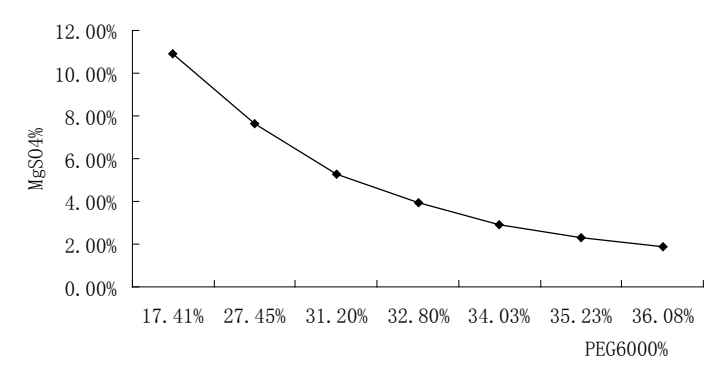

Figure 2 The phase diagram formed by PEG6000/MgSO4 two-phase system

\section{Effect on distribution behavior of nattokinase with different two-phase aqueous system} was studied.The crude enzyme solution were added to PEG/( $\left.\mathrm{NH}_{4}\right)_{2} \mathrm{SO}_{4}$ and $\mathrm{PEG6000/ \textrm {MgSO } _ { 4 }}$ two-phage aqueous system respectively.The solution was mixed with mixing device.Up volum,down volum and its enzyme activity were determined respectively after resting.Table 1 shows that distribution behavior of nattokinase in PEG400/( $\left.\mathrm{NH}_{4}\right)_{2} \mathrm{SO}_{4}$ two-phase aqueous system. Table 2 shows that distribution behavior of nattokinase in $\mathrm{PEG6000/MgSO}_{4}$ two-phase aqueous system.All of the recovery rates of nattokinase with PEG400/( $\left.\mathrm{NH}_{4}\right)_{2} \mathrm{SO}_{4}$ two-phase aqueous system were around $50 \%$.The highest recovery rate of nattokinase with $\mathrm{PEG6000/ \textrm {MgSO } _ { 4 }}$ two-phase aqueous system was $37.89 \%$.The recovery rate of nattokinase with PEG400/( $\left.\mathrm{NH}_{4}\right)_{2} \mathrm{SO}_{4}$ two-phase aqueous system was higher the recovery rate of nattokinase with $\mathrm{PEG6000/ \textrm {MgSO } _ { 4 }}$ two-phase aqueous system.Research shows that, the hydrophobicity of PEG and phase viscosity increases as the molecular weight increases, and the phase boundary tension between two phases increases, which is not conductive to the protein into PEG phase[7].If higher recovery rate of protein 
is expected to obtain,the molecular weight of PEG should be reduced. Therefore, PEG400/( $\left.\mathrm{NH}_{4}\right)_{3} \mathrm{SO}_{4}$ two-phase aqueous svstem was selected for the extraction of nattokinase.

Table 1 Distribution behavior of nattokinase in PEG400/( $\left.\mathrm{NH}_{4}\right)_{2} \mathrm{SO}_{4}$ two-phase aqueous system

\begin{tabular}{lllll}
\hline $\begin{array}{l}\text { PEG40 } \\
0 \%\end{array}$ & $\begin{array}{l}\left(\mathrm{NH}_{4}\right)_{2} \\
\mathrm{SO}_{4} \%\end{array}$ & $\mathrm{R}$ & $\mathrm{K}$ & $\mathrm{Yt}$ \\
\hline 25 & 22 & 1.18 & 1.14 & 57.36 \\
17 & 24 & 0.74 & 1.59 & 54.06 \\
16 & 24 & 0.5 & 2.66 & 57.08 \\
13 & 29 & 0.35 & 2.79 & 49.40 \\
20 & 25 & 0.81 & 1.82 & 59.58 \\
\hline
\end{tabular}

Table 2 Distribution behavior of nattokinase in PEG6000/MgSO 4 two-phase aqueous system.

\begin{tabular}{lllll}
$\mathrm{PEG60}_{0}$ & $\mathrm{MgSO}_{4}$ & $\mathrm{R}$ & $\mathrm{K}$ & $\mathrm{Yt}$ \\
$00 \%$ & $\%$ & & & \\
\hline
\end{tabular}

\begin{tabular}{lllll}
11 & 18 & 0.61 & 1 & 37.89 \\
8 & 28 & 0.35 & 0.82 & 22.30 \\
6 & 30 & 0.20 & 1 & 16.67 \\
4 & 33 & 0.16 & 1.36 & 17.87 \\
3 & 37 & 0.12 & 0.68 & 7.54 \\
\hline
\end{tabular}

Extraction of nattokinase with PEG400/( $\left.\mathrm{NH}_{4}\right)_{2} \mathrm{SO}_{4}$ two-phase aqueous system was studied. The mass fraction of $\left(\mathrm{NH}_{4}\right)_{2} \mathrm{SO}_{4}$ was $25 \%$, the addition of crude enzyme was $10 \%$.Effect on extraction of nattokinase with the mass fraction of $20 \%$ 、22\%、24\%、26\%、28\% PEG400 were studied respectively. The results are shown in table 3. With the increase of the mass fraction of PEG400,R and Yt of nattokinase increase, $\mathrm{K}$ of nattokinase increases first and then decreases. The higher mass fraction of PEG400 is conductive to the extration of nattokinase. But R increased with the increase of the mass fraction of PEG400,up phase volum enlarged, which was inconductive to enrichment of nattokinase.So the mass fraction of PEG400 also shoulds not be too big.As the mass fration of PEG400 was $24 \%$ and $28 \%$,the recovery rate of nattokinase almost equal. When the mass fraction of PEG400 was 28\%,R was smaller. Comprehensive consideration,the mass fration of PEG400 was determined to be $24 \%$.

The mass fraction of PEG400 was 24\%, the addition of crude enzyme solution was 10\%.Effect on extraction of nattokinase with the mass fraction of $21 \% 、 23 \% 、 25 \% 、 27 \% 、 29 \%\left(\mathrm{NH}_{4}\right)_{2} \mathrm{SO}_{4}$ were studied respectively. The results are shown in table 4 . With the increase of the mass fraction of PEG400, $\mathrm{R}$ of nattokinase increase, $\mathrm{K}$ and $\mathrm{Yt}$ of nattokinase increases first and then decreases. When the mass fraction of $\left(\mathrm{NH}_{4}\right)_{2} \mathrm{SO}_{4}$ was $27 \%, \mathrm{~K}$ and $\mathrm{Yt}$ of nattokinase is the highest.So the mass fration of $\left(\mathrm{NH}_{4}\right)_{2} \mathrm{SO}_{4}$ was determined to be $27 \%$.

The mass fraction of PEG400 was 24\%, the mass fraction of $\left(\mathrm{NH}_{4}\right)_{2} \mathrm{SO}_{4}$ was $27 \%$. Effect on extraction of nattokinase with addition of $5 \%, 10 \% 、 15 \%, 20 \% 、 25 \%$ crude enzyme were studied respectively. The results are shown in table 5 . With the increase of the addition of crude enzyme, $\mathrm{R}$ and Yt of nattokinase increase,K of nattokinase decreases. When the addition of crude enzyme was $15 \%, \mathrm{Yt}$ of nattokinase is the highest. So the addition of crude enzyme was determined to be $27 \%$.

The mass fraction of PEG400 was 24\%, the mass fraction of $\left(\mathrm{NH}_{4}\right)_{2} \mathrm{SO}_{4}$ was $27 \%$, the addition of crude enzyme was $15 \%$. The content of protein and enzyme activity of nattokinase in up phase was determined. The results are shown in table 6 .The recovery rate of nattokinase reached $86 \%$,the purification of nattokinase reached 2.11. 
Table 3 Effect on extraction of nattokinase with the mass fraction of PEG400

\begin{tabular}{|c|c|c|c|c|}
\hline $\begin{array}{l}\text { PEG40 } \\
0 \%\end{array}$ & $\begin{array}{l}\left(\mathrm{NH}_{4}\right)_{2} \\
\mathrm{SO}_{4} \% \\
\end{array}$ & $\mathrm{R}$ & $\mathrm{K}$ & $\mathrm{Yt}$ \\
\hline 20 & 25 & 0.82 & 1.82 & 59.87 \\
\hline 22 & 25 & 1.82 & 2.01 & 78.53 \\
\hline 24 & 25 & 1.94 & 2.94 & 85.08 \\
\hline 26 & 25 & 2.32 & 2.04 & 82.56 \\
\hline 28 & 25 & 5.00 & 1.60 & 88.89 \\
\hline \multicolumn{5}{|c|}{$\begin{array}{l}\text { Table } 5 \text { Effect on extraction of nattokinase with } \\
\text { addition of crude enzyme }\end{array}$} \\
\hline \multicolumn{2}{|c|}{$\begin{array}{l}\text { Addition of } \\
\text { crude enzyme (\%) }\end{array}$} & $\mathrm{R}$ & $\mathrm{K}$ & $\mathrm{Yt}$ \\
\hline 5 & & 0.97 & 3.12 & 75.16 \\
\hline 10 & & 2.62 & 2.12 & 84.74 \\
\hline 15 & & 2.78 & 2.08 & 85.25 \\
\hline 20 & & 4.42 & 1. 98 & 89.74 \\
\hline 25 & & 5.05 & 1.85 & 90.33 \\
\hline
\end{tabular}

Table 4 Effect on extraction of nattokinase with the mass fraction of $\left(\mathrm{NH}_{4}\right)_{3} \mathrm{SO}_{4}$

\begin{tabular}{lllll}
\hline $\begin{array}{l}\text { PEG40 } \\
0 \%\end{array}$ & $\begin{array}{l}\left(\mathrm{NH}_{4}\right)_{2} \\
\mathrm{SO}_{4} \%\end{array}$ & $\mathrm{R}$ & $\mathrm{K}$ & $\mathrm{Yt}$ \\
\hline 24 & 21 & 1.28 & 1.12 & 58.91 \\
24 & 23 & 1.38 & 1.77 & 70.95 \\
24 & 25 & 1.94 & 1.94 & 79.01 \\
24 & 27 & 2.62 & 2.12 & 84.74 \\
24 & 29 & 1.75 & 1.39 & 70.87 \\
\hline
\end{tabular}

Table 6 Recovery of nattokinase enzyme activity and total protein two-phase aqueous system

\section{Conclusion}

Compared with PEG6000/MgSO 4 two-phase aqueous system, PEG400/( $\left.\mathrm{NH}_{4}\right)_{2} \mathrm{SO} 4$ two-phase aqueous system was more suitable for extraction of nattokinase. Various factors affecting the extraction of nattokinase with PEG400/( $\left(\mathrm{NH}_{4}\right)_{2} \mathrm{SO}_{4}$ two-phase aqueous system were studied. The mass fraction of PEG400 was determined to be $24 \%$, The mass fraction of $\left(\mathrm{NH}_{4}\right)_{2} \mathrm{SO}_{4}$ was determined to be $27 \%$,crude enzyme was determined to be $15 \%$. Under these conditions,purification of nattokinase reached 2.11. This sudy not only has opened up new avenues for separation and purification of nattokinase,but also broaden the scope of application in biological macromolecules with two-phase aqueous system. 


\section{References}

[1] Changsu Wang,Xiaotong Sun,Jie Yu et al.Identification of nattokinase high activity strain BN-05 andoptimization of the fermentation technology [J].China Brewing, 2014, 33 (1) : 262-267. (in Chinese)

[2]Yanmao Shi,Yuehua Ma,Ming Yang.Research of separation and purification method of nattokinase [J]. China Brewing, 2014，33（1）: 262-267. (in Chinese)

[3]Chunhong Ma,Hong Zhu,Liang Wang. Application progress of two-phase aqueous extraction technology [J].Spectroscopy Laboratory. 2010, 5 (27) : 38-43. (in Chinese)

[4] Xiaohui Xiong,Rui Li,Lixia Lu. Study on extraction and characterization of nattokinase. Food and fermentation industry [J]. 2006, 6 (32) : 122-126. (in Chinese)

[5]Xia Li,Xun Liao,Wei Wei.Study on aqueous two phase exteation of trypsin [J].Journal of Sichuan University(natural science edition) 2013, 5 (50) : 1141-1144. (in Chinese)

[6]Bo Li,Fei Lu,Junhe Zhang. Study on separation and purification of a -amylase with two-phase aqueous system [J]. Science and technology of food industry. 2006, 8 (27) : 77-80(in Chinese)

[7]Duixi Cao,Zheng Du,Yuting Han.Study on extraction of Papain with two-phase aqueous system [J].The processing of agricultural products. 2010, 10: 66-70 (in Chinese) 